\title{
Making Sense of Global Gold Mining
}

Boris Verbrugge and Maria Eugenia Robles Mengoa

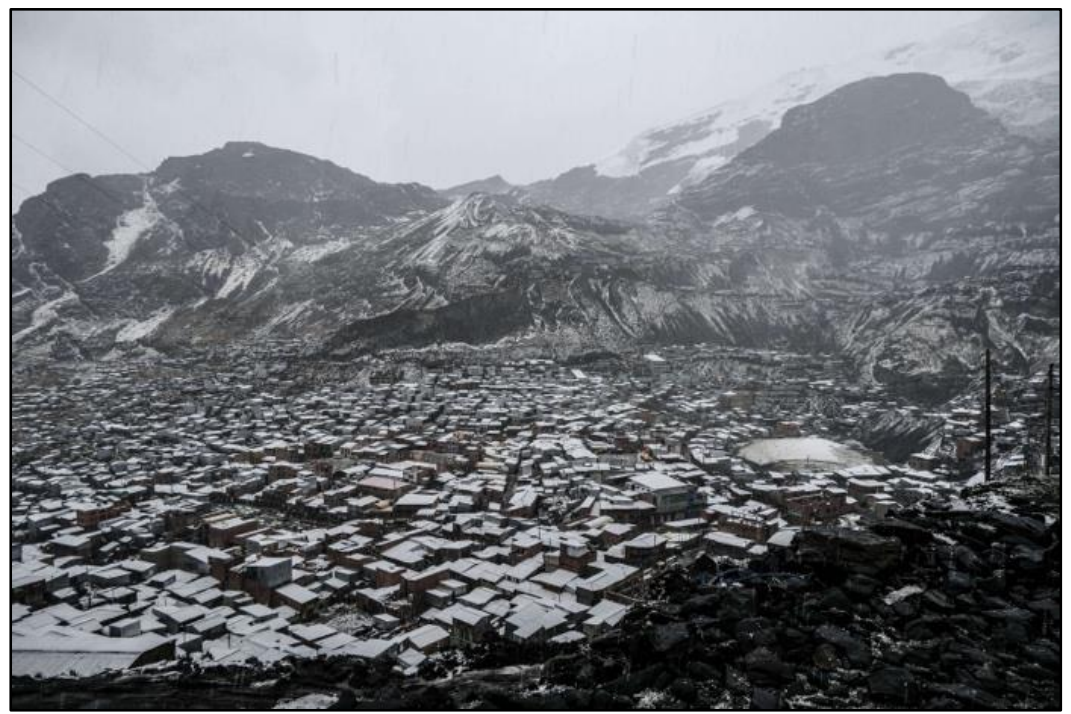

Photo source: Maria Eugenia Robles Mengoa

Keywords: gold, artisanal and small-scale mining (ASM), minerals, commodity frontiers, anthropological fieldwork

\section{Dual Gold Mining Economy? A}

The history of mining is often conceived of as a linear evolution from traditional, premodern forms of mining to industrial mining undertaken by global corporations (Lynch, 2003). Yet the global gold mining economy now harbors an incredibly wide range of gold mining activities that operate with varying levels of capital- and labor intensity. At one end of the spectrum we find what is commonly referred to as artisanal and smallscale gold mining: low-tech, labor-intensive gold mining activities that usually operate without the legal recognition of the government. On the other side of the spectrum, we find open-pit and underground mining operations undertaken by large mining companies. Yet in-between these extremes, there are a growing number of gold mining operations that defy easy categorization. A good example is the growing number of Chinese-backed gold mining operations in countries like

\section{Correspondence:}

Boris Verbrugge, boris.verbrugge@kuleuven.be.

Cite this article:

Verbrugge, B. and M.E. Robles Mengoa. 2020. "Making Sense of Global Gold Mining." Commodity Frontiers 1: 7-11. doi: 10.18174/CF.2020a17961.

Commodity Frontiers is an open-access journal edited by the CFI Editorial Board, Mindi Schneider, senior editor. Read it online at Commodity Frontiers, or our website, commodityfrontiers.com.

This work is licensed under a Creative Commons Attribution-NonCommercial 4.0 International License. 
Madagascar, Ghana, and the Philippines. While these operations involve significant investments, and often operate with the blessing of local politicians, they remain illegal in the eyes of national governments, and fall short of being full-blown industrial mining operations.

Earlier research on gold mining has largely failed to make sense of this diversity. Instead, it has fostered a dominant view of a dual gold mining economy that is split between subsistence-oriented artisanal and small-scale gold mining; and modern, capitalist industrial mining. Moreover, social scientists that focus on gold mining (many of whom are anthropologists) have privileged an analysis of dynamics inside gold mining areas, without accounting for diversity across areas.

In our own research, we set out to develop an explanatory framework for understanding diversity in global gold mining. This required a move away from the dualist and localist focus that characterized earlier research. The results of this exercise were recently published in the form of an edited volume, which couples an analysis of systemic trends in global gold mining to thirteen country case studies in Africa, Latin America, and Asia (Verbrugge \& Geenen, 2020a). In this contribution, we want to briefly elaborate on the analytical and conceptual challenges that we encountered.

\section{The Perils of Researching the Gold Mining Frontier}

Research on dynamics inside gold mining areas inevitably requires an intimate and longterm engagement with the field. Yet as Ballard and Banks (2003) have warned, "mining is no ethnographic playground", and presents researchers with a variety of ethical and methodological challenges. While this is certainly the case of industrial mining, these challenges are even more outspoken where it concerns smaller, informal gold mining activities. Our own project involved empirical research in gold rush areas in Peru, Colombia, the DRC, and the Philippines. The following reflections were made by Eugenia Robles, a female, Bolivian-Peruvian anthropologist who is one of two $\mathrm{PhD}$ students involved in the project.

"Most of these mining areas are situated in remote and rugged terrain, and transport is scarce and expensive. Moreover, the state does not hold a monopoly on violence, and armed robbery and murder are common along the way. While getting to a mining area is a risky undertaking, gaining access to the research site and to respondents is even trickier. Credibility is key, and entering a mining area without a local contact is to put yourself at risk of being greeted with suspicion or even threats. The few times when I entered mining areas without a local contact, people did not want to share any information, and I was warned to leave the site.

Even when you eventually gain access to respondents, they may still be reluctant to share (certain) information, let alone to do so on record. In part, this is related to the fact that many of the mining activities are considered illegal by the government. Risks are even more outspoken when there is a presence of armed groups, such as paramilitary groups in Colombia, and criminal bands that engage in sex trafficking and armed robbery in Peruvian mine sites. In these cases, even a small mistake or the wrong question or answer can prove extremely costly, for researcher and respondent alike. This raises important ethical questions, not least with regards to respondent safety.

Aside from these contextual challenges, it is also important to consider how certain personality traits of the researcher, and particularly gender and race, affect local perceptions about the researcher, and consequently his or her ability to gain access to information.

Mining is a masculine activity par excellence, and women are considered weak (Colombia), fragile (the Philippines) or carriers of bad 
luck (Peru). In my own experience, at least initially, female researchers are greeted with less suspicion when gathering "sensitive" or high-risk data. Yet in some cases, this initial openness gave way to unease, as respondents felt entitled to ask for a "reward" after having given their testimony. Likewise, while the color of my skin resulted in me being perceived as a local, it also meant that I faced many of the risks that young Latin-American women face on an everyday basis. There is a higher chance on being verbally or physically harassed, or to suffer sexual violence.

In contrast, my encounters with foreign white researchers (both male and female) suggest that the color of their skin exerts a certain symbolic power, and is associated with having money and authority. These expectations, as well as the mere fact of being 'different', raises the curiosity of locals, who might be more inclined to enter into a conversation. More broadly, being white comes with a kind of 'protective layer', which in many cases reduces the risk of being harmed or harassed, contrary to what a local researcher would experience."

In addition to these methodological, ethical, and sometimes very personal challenges, researchers also face conceptual challenges. For instance, the often taken-for-granted distinctions between small-scale and largescale, formal and informal, or legal and illegal mining make little sense when confronted with messy realities on the ground.

What is branded by government officials as 'illegal' mining may well be seen as perfectly legitimate by local communities (Lahiri-Dutt, 2004). Vice versa, industrial miners operating with the blessing of the national government may be seen as foreign intruders who threaten local livelihoods. Here, the challenge is to understand the registers through which different people view reality, and to translate these registers into concepts that more accurately reflect reality. It also raises questions with regards to the position of researchers, who understandably tend to empathize with the weak (there is a strong tradition of activist research on mining).

\section{T Tnderstanding Global Connections}

Insofar as structural trends in global gold mining were taken into consideration in earlier research, they were mostly seen as an external force, and consequently remained outside the scope of the actual analysis. Such is the case when reference is made to how structural adjustment policies championed by international lenders, and their devastating impact on local livelihoods, are 'pushing' people into gold mining (Hilson \& Potter, 2005), or how rising gold prices 'pull' people to the mines. Yet so far, our understanding of how more complex frontier dynamics processes of expansion and contraction, changes in land and labor regimes, and technological innovations - intersect with structural trends in global gold mining remains utterly limited.

While there exist detailed analyses of particular episodes in the history of gold mining in particular places (prime examples include the nineteenth-century US gold rushes or (pre-)colonial gold mining in South Africa and Ghana), no-one had undertaken a comprehensive historical analysis of global gold mining.

While it was not our ambition to create such a comprehensive historical overview, we did require a more systematic understanding of structural trends in gold mining during the last century. We took a multi-pronged approach to data collection, compiling insights from existing literature, making our own analysis of historical gold production data, and conducting interviews with industry experts. This combination of methods allowed us to confirm and extend earlier analyses (Mudd, 2007) that in recent decades, gold mining entered a protracted phase of global expansion, whereby it has moved from its historical core (South Africa, the United States, Australia, Canada, and Russia) into a wide range of new gold mining destinations 
(the 'rest of the world' in the graph below). Prime examples include China (the world's top consumer and producer of gold),

Indonesia, Ghana, and Peru. While some of these countries may well have a longer history of gold mining, the sheer scale of the ongoing expansion is beyond anything that has been seen before.

Finally, we were left with the task of bridging the divide between global trends and local dynamics. A first exercise involved applying Jason Moore's concept of the commodity frontier to the case of gold mining (Verbrugge \& Geenen, 2019). We argued that, in the face of the systemic challenges described above, the gold commodity frontier has undergone a simultaneous

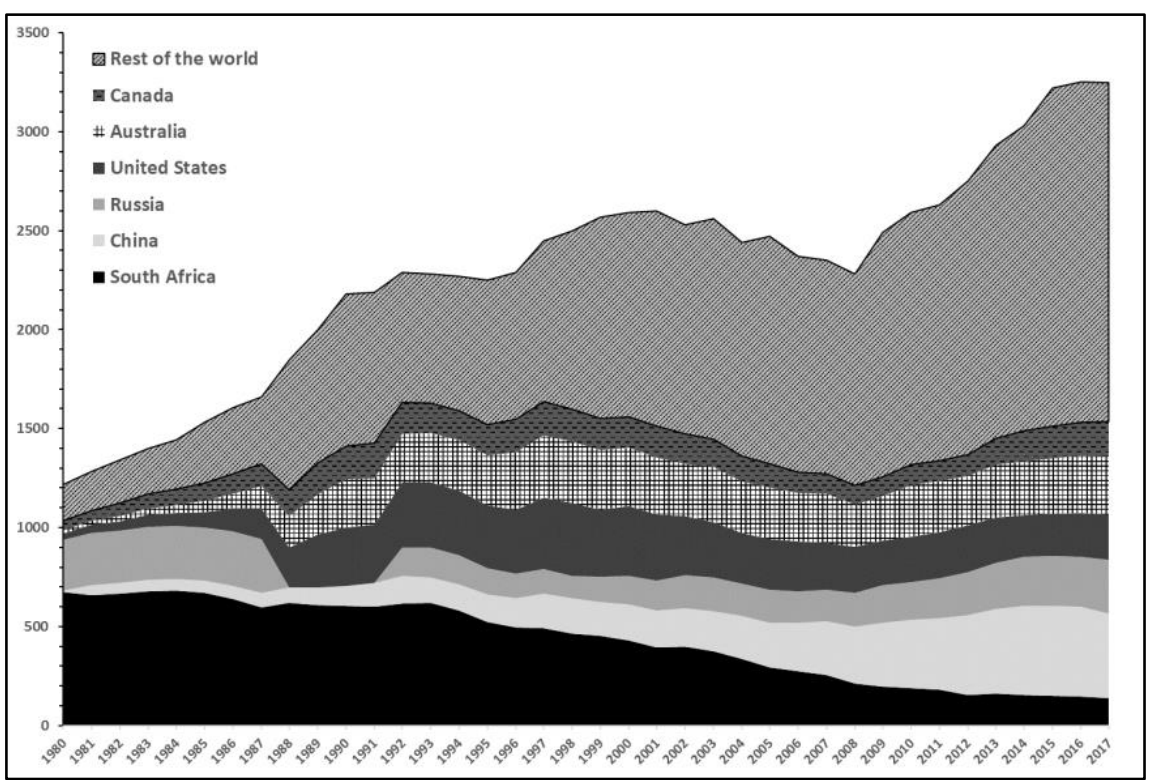

process of widening (geographical expansion) and deepening (social and technological innovations). Building on these ideas, we then turned to the literature on global value chains and global production networks. The framework we then developed on the basis of this (and other) literature, which we refer to as the global gold production system, provided the theoretical-analytical basis for our recent book

Figure 1. The Globalization of Global Gold Mining. Source: Verbrugge \& Geenen, 2020b

At the same time, global gold production is facing a number of systemic challenges. A first set of challenges is related to increased resistance to mining on the parts of governments and local communities, who often feel left behind by the global gold mining boom. A second set of challenges is related to rising cost pressures, due to (amongst other things) rising energy costs, labor costs, and the costs related to operating in increasingly remote environments. A third and final set of challenges is related to increased scarcity: the world is gradually running out of easily accessible gold deposits, and several observers are convinced that we have reached the point of 'peak gold' (the point at which maximum global production is reached).
(Verbrugge \& Geenen, 2020a).

In the first part of this book, we describe three structural trends in global gold production: global expansion, technological innovation, and informalization (i.e. an increased reliance on cheap and flexible labor). In the second part of the book, we invited colleagues who conduct empirical research on gold mining across the globe to apply our framework to 'their' case.

Together, these case studies detail how the global gold production system 'touches ground' in particular places, where it intersects with institutional and ecological structures. This process of touching ground produces what we refer to as gold mining crystallizations: dynamic and interconnected sets of gold mining activities with varying degrees of capital- and labor intensity, and diverging social relations of production. In this way, we are able to account for the growing diversity that characterizes contemporary gold mining. 


\section{References}

Ballard, C., \& Banks, G. (2003). Resource wars: the anthropology of mining. Annual review of anthropology, 32(1), 287-313.

Hilson, G., \& Potter, C. (2005). Structural adjustment and subsistence industry: artisanal gold mining in Ghana. Development and change, 36(1), 103-131.

Lahiri-Dutt, K. (2004). Informality in mineral resource management in Asia: Raising questions relating to community economies and sustainable development. Natural Resources Forum 28(2), 123-132).

Lynch, M. (2003). Mining in world history. London: Reaktion Books.

Moore, J. W. (2000). Sugar and the expansion of the early modern world-economy: Commodity frontiers, ecological transformation, and industrialization. Review (Fernand Braudel Center), 409433.

Mudd, G. M. (2007). Global trends in gold mining: Towards quantifying environmental and resource sustainability. Resources Policy 32(1), 42-56.

Verbrugge, B., \& Geenen, S. (2019). The gold commodity frontier: A fresh perspective on change and diversity in the global gold mining economy. The Extractive Industries and Society 6(2), 413423.

Verbrugge, B, \& Geenen, S. (2020a). Global gold production touching ground: Expansion, informalization, and technological innovation. London: Palgrave Macmillan.

Verbrugge, B., \& Geenen, S. (2020b). Global expansion. In B. Verbrugge \& S. Geenen (Eds.), Global gold production touching ground (pp. 53-67). London: Palgrave Macmillan.

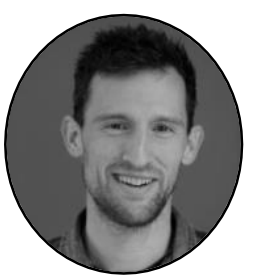

Boris Verbrugge is a post-doctoral researcher at the Institute of Development Policy (IOB, University of Antwerp), and at the Research Institute for Work and Society (HIVA-KU Leuven). His research interests relate to working conditions in global value chains, with a primary focus on extractives.

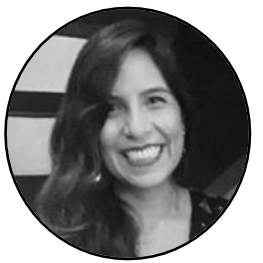

Maria Eugenia Robles Mengoa is a $\mathrm{PhD}$ Candidate at the Institute of Development Policy (IOB, University of Antwerp). She has conducted field research in artisanal- and small-scale gold mining communities in Peru, Bolivia, Colombia, and the Philippines; focusing (amongst other things) on gender-based violence and illicit trade flows. 